INVITED ARTICLE

\title{
Cleistanthus collinus Poisoning
}

\author{
Alladi Mohan ${ }^{1}$, Janjam Harikrishna ${ }^{2}$ \\ Keywords: Cleistanthus collinus, Clinical presentation, Outcome, Poisoning, Treatment. \\ Indian Journal of Critical Care Medicine (2019): 10.5005/jp-journals-10071-23317
}

\section{INTRODUCTION}

Poisoning is a major public health problem world over. Acute deliberate self-poisoning is an important cause of admission to intensive care units (ICUs) in India. In a study published from Delhi 9.3\% of total ICU admissions were due to acute poisoning. ${ }^{1}$ According to the World Health Organization, the global crude suicide rate in 2016 was $10.6 / 100,000$ population. ${ }^{2}$ In India, it was $16.3 / 100,000$ population. Suicide is the second leading cause of death among $15-$ 29-year-old population globally. ${ }^{3}$ Suicide accounted for $1.4 \%$ of all deaths worldwide, making it the 18th leading cause of death in 2016; $79 \%$ of all suicides occurred in low- and middle-income countries. ${ }^{3}$ According to the National Crime Record Bureau, poisoning is the second most common mode of suicide in India. ${ }^{4}$ Consumption of toxic plants is one of the modes of deliberate self-poisoning, especially in the rural population. In a study ${ }^{5}$ published from the National Poisoning Information Centre, All India Institute of Medical Sciences, New Delhi, consumption of plant material constituted $1.7 \%$ of all poisonings. In another study ${ }^{6}$ from Vellore, plant poisoning constituted $8 \%$ of total poisoning of which Cleistanthus collinus constituted $77 \%$, and yellow oleander $23 \%$. At the Sri Venkateswara Institute of Medical Sciences, Tirupati, plant poisoning constituted $5.3 \%$ of all cases of poisoning and C. collinus was the most common plant poison. ${ }^{7}$ These observations suggest that C. collinus is the most common plant poisoning encountered in South India. In this article, we review the mechanism of toxicity, clinical manifestations, and management of $C$. collinus poisoning.

Cleistanthus collinus, belonging to the family Euphorbiaceae, is a small tree with elliptical leaves and silky villous inflorescence. It is commonly found in deciduous dry hilly forests of South India, Sri Lanka and Malaysia. ${ }^{8}$ It is known by various names in different languages in India, Garari (Hindi), Vadisaaku (Telugu), Oduvanthalai (Tamil), and Odaku (Malayalam). ${ }^{9}$ All parts of the plant are highly poisonous. The leaves are frequently used as a cattle poison and abortifacient in South India. ${ }^{10}$ Cleistanthus collinus is the most common plant poison encountered in rural South India, especially in women; probably due to the easy availability and knowledge of the toxic nature of the plant. The leaves are consumed either by chewing or by making a decoction of the leaves. ${ }^{11}$

\section{Toxic Principles}

Alcohol extracts of the leaves of $C$. collinus plant parts revealed arylnaphthalene lignan lactones diphyllin, cleistanthins $A, B$, cleistanone, ${ }^{12}$ of which cleistanthins $A, B$ are considered to be responsible for major toxic effects in humans. However, subsequent analysis of aqueous extracts of the leaves of $C$. collinus by gas chromatography and mass spectrometry (GC-MS) revealed 3-O-methyl-D-glucose (41.6\%), benzenetriol (pyrogallic acid,
${ }^{1}$ Division of Pulmonary, Critical Care and Sleep Medicine, Department of Medicine, Sri Venkateswara Institute of Medical Sciences, Tirupati, Andhra Pradesh, India

${ }^{2}$ Department of Critical Care Medicine, St John's Medical College, Bengaluru, Karnataka, India

Corresponding Author: Alladi Mohan, Division of Pulmonary, Critical Care and Sleep Medicine, Department of Medicine, Sri Venkateswara Institute of Medical Sciences, Tirupati, Andhra Pradesh, India, Phone: +91-877-2288016, e-mail: alladimohan@rediffmail.com

How to cite this article: Mohan A, Harikrishna J. Cleistanthus collinus Poisoning. Indian J Crit Care Med 2019;23(Suppl 4):S256-S259.

Source of support: Nil

Conflict of interest: None

pyrogallol) (25.1\%), $n$-hexadecanoic acid (10.6\%), heptacosane (4.4\%), and 1,2-benzenedicarboxylic acid, disooctyl ester (3.5\%). ${ }^{13}$ The GC-MS analysis did not demonstrate the presence of arylnaphthalene lignan lactones, which were proposed as the toxic principles of $C$. collinus. As the common mode of life threatening $C$. collinus poisoning is by consuming the aqueous extract (decoction) of the leaves, absence arylnaphthalene lignan by GC-MS analysis raises doubts on the role of these compounds in the causation of toxicity of $C$. collinus poisoning. Further research is warranted to identify the toxic principles of $C$. collinus.

\section{Mechanism of Toxicity}

A study ${ }^{14}$ of the effects of cleistanthin A and B on tissue culture lines has shown that it arrests the cell cycle progression from $G 1$ to $S$ phase by inhibiting the incorporation of thymidine and uridine in DNA and RNA, respectively. At high doses, it causes breaks in the DNA strands and causes apoptosis. ${ }^{14}$ Oral administration of aqueous extracts of $C$. collinus in albino Wistar rats and Himalayan Rabbits produced significant depletion of glutathione and adenosine triphosphatases (ATPases) in various tissues such as liver, kidney, and brain. Histopathologic examination revealed degenerative changes in hepatocytes, glomerulus and gliosis in brain. ${ }^{8}$ These findings suggest that the major mechanism of $C$. collinus toxicity is due to the oxidative stress induced by inhibition of thiol/thiol dependent enzymes. Based on the study of effects aqueous extract of $C$. collinus on the rat renal brush border membrane (BBM) proton pump activity, vacuolar-type $\mathrm{H}^{+}$-ATPase (V-ATPase) enzyme activity and ATP, adenosine diphosphate (ADP), and adenosine monophosphate (AMP) levels, it was found that the aqueous extract of $C$. collinus causes uncoupling of oxidative phosphorylation and leads to increased ADP levels, which in turn inhibit the V-ATPase in the BBM of distal renal tubule. ${ }^{15}$ This is likely to be the mechanism causing distal renal tubular acidosis in humans.

(c) The Author(s). 2019 Open Access This article is distributed under the terms of the Creative Commons Attribution 4.0 International License (https://creativecommons. org/licenses/by-nc/4.0/), which permits unrestricted use, distribution, and non-commercial reproduction in any medium, provided you give appropriate credit to the original author(s) and the source, provide a link to the Creative Commons license, and indicate if changes were made. The Creative Commons Public Domain Dedication waiver (http://creativecommons.org/publicdomain/zero/1.0/) applies to the data made available in this article, unless otherwise stated. 
Administration of aqueous extracts of $C$. collinus leaves resulted in hypotension and death in rats. It also prolonged the hypotensive effect of acetylcholine. In guinea pigs, smooth muscle preparation it exerted the alpha receptor blocking property and inhibited the a-receptor action of phenylephrine. ${ }^{16,17}$ These observations suggest that aqueous extracts of $C$. collinus leaves have anti- $a$-adrenergic and anticholinergic properties and could be the likely underlying mechanism for shock and neuromuscular paralysis caused by $C$. collinus. Boiled aqueous extracts of $C$. collinus leaves at low doses cause transient tachycardia, increased contractility, and higher doses cause arrhythmia and cardiac arrest in rat and frog heart preparations and could be the reason for cardiotoxic effects of C. collinus. ${ }^{18}$ Intraperitoneal injection of leaf extracts of $C$. collinus in rats caused neuromuscular blockade that was reversed with the administration of neostigmine and aminipyridin. ${ }^{19}$ This could probably constitute the reason for myesthenic crisis like syndrome in C. collinus poisoning.

\section{Clinical Presentation}

Various clinical manifestations of $C$. collinus poisoning in humans are listed in Table 1. ${ }^{6,20,21}$ Comparison of clinical profile of patients with C. collinus poisoning in some of the published studies from India, as shown in Table 2.

Mortality ranged from $18 \%$ to $43 \%$; the most common causes of death were refractory hypotension, respiratory failure and sudden ventricular arrhythmia (Table 2). 6,21-24 Predictors of mortality were lower serum potassium, older age, presence of chronic disease, and consumption of decoction. In another study ${ }^{21}$ delayed presentation, higher acute physiology and chronic health evaluation II (APACHE II) score, presence of acute kidney injury (AKI), shock, metabolic acidosis, hyponatremia, and need for mechanical ventilation emerged as risk factors for mortality.

\section{Management}

In patients presenting with a history of plant poisoning, especially in South India, where C. collinus poisoning is more common, it can be identified by recognizing the classical clinical manifestations of vomiting, abdominal pain with life threatening manifestations such as acute respiratory failure, AKI, shock, myesthenic crisis like syndrome, altered mental status, and cardiac conduction abnormalities. Patients with these manifestations should be investigated for normal anion-gap metabolic acidosis, kaliuresis, and hypokalemia, which are classical manifestations of $C$. collinus poisoning.

As in the management of any other poisoning patient, initial attention should be given to the assessment of circulation, airway, and breathing (CAB). Patients with C. collinus poisoning should ideally be admitted to ICU and closely monitored for cardiorespiratory manifestations, as these patients may be normal or with minimal symptoms at the time of initial presentation;

Table 1: Clinical manifestations of Cleistanthus collinus poisoning in humans

\begin{tabular}{lll}
\hline System & Common & Uncommon \\
\hline Gastrointestinal & Vomiting, abdominal pain, and diarrhea & Constipation, abdominal distension, dysphagia, and salivation \\
Renal & Distal RTA, kaliuresis, and hypokalemia & AKI \\
Neurological & $\begin{array}{l}\text { Altered sensorium, giddiness, and abnormal } \\
\text { vision }\end{array}$ & $\begin{array}{l}\text { Muscle weakness, seizure, headache, altered speech, ptosis, } \\
\text { tremor, and myesthenic crisis like syndrome }\end{array}$ \\
Cardiovascular & $\begin{array}{l}\text { Bradycardia, tachycardia, hypotension, and } \\
\text { abnormal ECG }\end{array}$ & $\begin{array}{l}\text { Chest pain } \\
\text { Respiratory }\end{array}$ \\
Systemic & Dyspnea and tachypnea & Hypoxemia, cough, bradypnea, ARDS, and respiratory arrest \\
\hline
\end{tabular}

AKI, acute kidney injury; RTA, renal tubular acidosis; ECG, electrocardiogram; ARDS, acute respiratory distress syndrome.

Data source: ref. 6, 20, and 21.

Table 2: Comparison of clinical profile of patients with Cleistanthus collinus poisoning in some of the published studies from India

\begin{tabular}{|c|c|c|c|c|c|}
\hline Variable & Shankar ${ }^{6}$ & Subrahmanyam ${ }^{22}$ & Devaprabhu ${ }^{23}$ & Bammigatti $^{24}$ & Mohan $^{21}$ \\
\hline Place & Vellore & Puducherry & Vellore & Puducherry & Tirupati \\
\hline Duration of study & 1990-1999 & 1998-2000 & 2000-2006 & 2010 & 2010-2014 \\
\hline $\begin{array}{l}\text { No. of patients } \\
\text { studied }\end{array}$ & 127 & 46 & 114 & 51 & 56 \\
\hline Age (mean $\pm S D)$ & $29 \pm 11$ & ND & ND & 32 & $37 \pm 13$ \\
\hline Male:female & $2: 3$ & $2: 3$ & $2: 3$ & $1: 1$ & $1: 1$ \\
\hline $\begin{array}{l}\text { Common clinical } \\
\text { features }\end{array}$ & $\begin{array}{l}\text { Hypokalemia hypona- } \\
\text { tremia vomiting } \\
\text { altered sensorium } \\
\text { abdominal pain }\end{array}$ & $\begin{array}{l}\text { Vomiting, epigastric } \\
\text { pain, breathlessness, } \\
\text { visual disturbances } \\
\text { hypokalemia, and } \\
\text { hyponatremia }\end{array}$ & Hypokalemia & $\begin{array}{l}\text { Abdominal pain, } \\
\text { vomiting, giddiness, } \\
\text { and hypokalemia }\end{array}$ & $\begin{array}{l}\text { Hypokalemia, neutrophilic } \\
\text { leukocytosis, acute kidney } \\
\text { injury, shock, cardiac arrhyth- } \\
\text { mias, and neuromuscular } \\
\text { weakness }\end{array}$ \\
\hline Mortality (\%) & 30 & 32 & 43 & 18 & 38 \\
\hline Duration to death & 3 (median, days) & 3 (median, days) & ND & 4.2 (median, days) & $\begin{array}{l}\text { 14/17 patients* died within } \\
7 \text { days of consumption of } \\
\text { Cleistanthus collinus }\end{array}$ \\
\hline
\end{tabular}

*Overall, 21/56 (38\%) patients had poor outcome; 17 patients died, 4 of the severely ill patients sought discharge from the hospital against medical advise $\mathrm{SD}$, standard deviation; ND, not described 
once these manifestations develop patients rapidly deteriorate without appropriate treatment. Patients presenting with shock must be evaluated and treated appropriately with intravenous fluids, vasopressors; urine output should be carefully monitored. Continuous cardiac monitoring is indicated as these patients are more prone to the development of cardiac arrhythmias. Patients with cardiac arrhythmias should be evaluated for treatable causes like hypokalemia, severe metabolic acidosis, hypomagnesemia, and hypoxemia. When present, electrolyte abnormalities should be promptly treated. Patients with hypoxemia refractory to supplemental oxygen, refractory shock, and patients with obtunded sensorium who are unable to protect the airway should be intubated and initiated on mechanical ventilatory support.

\section{Gastric Decontamination}

There are no studies to address the benefit of gastric lavage in C. collinus poisoning. In poisoned patients, evidence to support the beneficial effects of gastric lavage is weak. ${ }^{25}$ However, as C. collinus poisoning is associated with high mortality patients with significant poisoning may be considered for gastric lavage if they present within 1 hour of consumption. Gastric lavage should not be administered to patients with altered sensorium without securing the airway.

\section{Activated Charcoal}

A single dose of $1 \mathrm{mg} / \mathrm{kg}$ body weight of activated charcoal may be considered in patients with $C$. collinus poisoning with an intact airway. Activated charcoal is contraindicated in patients with decreased sensorium, who are unable to protect their airway unless they are intubated. A study ${ }^{26}$ showed the beneficial effect of multiple dose-activated charcoal $(0.5 \mathrm{mg} / \mathrm{kg}$ every 6 hours for 48 hours) in the form of reduced complications such as hypokalemia, hypocalcemia, and death in patients with $C$. collinus poisoning. The results of this study should be viewed cautiously in view of the small sample size.

\section{Specific Treatment}

There is no specific antidote for $C$. collinus poisoning with a definitive mortality benefit. Patients with $C$. collinus poisoning should be monitored for electrolyte abnormalities. Hypokalemia, hyponatremia, and hypomagnesemia, when identified should be promptly treated, as these patients are at risk for the development of cardiac arrhythmias. Hypokalemia and hypomagnesemia make these patients more susceptible to the development of cardiac arrhythmias and make them refractory to standard treatment. Patients with AKI with oliguria and severe metabolic acidosis should be considered for renal replacement therapy. The role of prophylactic pacing with temporary cardiac pacing is uncertain. It may be considered in patients with severe bradycardia and electrocardiogram showing prolonged corrected QT (QTc) interval, as ventricular tachycardia, ventricular fibrillation, and sudden cardiac death can occur in these patients. However, the benefits of routine prophylactic temporary pacemaker insertion is not documented.

\section{Other Treatment Modalities}

In a patient with myesthenic crisis like syndrome, a case report ${ }^{11}$ documented the benefit of neostigmine. A trial of neostigmine should be considered in patients with $C$. collinus poisoning with myesthenic crisis like presentation and continued until full recovery if the initial dose shows clinical improvement. Studies $s^{8,15}$ in animal models have demonstrated that oxidative stress leads to lipid and protein peroxidation and interferes with cellular function. Therefore, $\mathrm{N}$-acetyl cysteine and other thiol containing compounds that have the ability to act as glutathione precursors and promote antioxidant properties of glutathione may reduce oxidative stress that has been produced by C. collinus poisoning. However, the benefits of these compounds has not been established.

\section{Conclusion}

Cleistanthus collinus is a common cause of plant poisoning encountered in rural south India. It is associated with high mortality and there is no definitive antidote. Consumption of the aqueous extract of the plant is associated with high mortality. Further research is required to identify putative toxic molecules in C. collinus, and also to identify definitive antidote. In the absence of definitive antidote, at present management of $C$. collinus poisoning remains symptomatic and supportive.

\section{References}

1. Singh O, Javeri Y, Juneja D, Gupta M, Singh G, Dang R. Profile and outcome of patients with acute toxicity admitted in intensive care unit: Experiences from a major corporate hospital in urban India. Indian J Anaesth 2011;55(4):370-374. DOI: 10.4103/0019-5049.84860.

2. World Health Organization, Available at URL:Word health statistics data visualizations dashboard. Available at URL: http://apps.who.int/gho/ data/node.sdg.3-4-viz-2?lang=en. Accessed on December 10, 2019.

3. World Health Organization, Suicide data. Available at URL: https:// www.who.int/mental_health/prevention/suicide/suicideprevent/ en/. Accessed on December 10, 2019.

4. National Crime Records Bureau, Accidental Deaths \& Suicides in India 2016. Available at URL: http://ncrb.gov.in/StatPublications/ ADSI/ADSI2016/chapter-2\%20suicides.pdf. Accessed on December 10, 2019.

5. Srivastava A, Peshin SS, Kaleekal T, Gupta SK. An epidemiological study of poisoning cases reported to the National Poisons Information Centre, All India Institute of Medical Sciences, New Delhi. Hum Exp Toxicol 2005;24(6):279-285. DOI: 10.1191/0960327105ht527oa.

6. Shankar V, Jose VM, Bangdiwala SI, Thomas K. Epidemiology of Cleistanthus collinus (oduvan) poisoning: clinical features and risk factors for mortality. Int J Inj Contr Saf Promot 2009;16(4):223-230. DOI: 10.1080/17457300903307094.

7. Arun Raja V, Mohan A, Harikrishna J, Sarma KVS. Prospective study of predictors of outcome in 159 patients with acute poisonining admitted in medical intensive care unit. J Assoc Physicians India 2015;63:88.

8. Sarathchandra G, Balakrishnamurthy P. Perturbations in glutathione and adenosine triphosphatase in acute oral toxicosis of Cleistanthus collinus: an indigenous toxic plant. Indian J Pharmacol 1997;29:82-85.

9. Asolkar LV, Kakkar KK, Chakre OJ, ed. Second Supplement to Glossary of Indian Medicinal Plants with Active Principles Part-1(A-K) (19651981). New Delhi: National Institute of Science Communication, Council for Scientific and Industrial Research; 2000. p. 214.

10. Viswanathan N, Joshi BS. Toxic contituents of some Indian plants. Curr Sci 1983;52(1):1-8.

11. Aleem MA, Paramasivam M. Spectrum of acute poisoning in villagers. J Assoc Physicians India 1993;43:859.

12. Ramesh C, Ravindranath N, Ram TS, Das B. Arylnaphthalide lignans from Cleistanthus collinus. Chem Pharm Bull 2003;51(11):1299-1300. DOI: 10.1248/cpb.51.1299.

13. Parasuraman S, Raveendran R, Madhavrao C. GC-MS analysis of leaf extracts of Cleistanthus collinus Roxb. (Euphorbiaceae). Int J Ph Sci 2009;1:284-286.

14. Pradheepkumar CP, Panneerselvam N, Shanmugam G. Cleistanthin A causes DNA strand breaks and induces apoptosis in cultured cells. Mutat Res 2000;464:185-193. DOI: 10.1016/S1383-5718(99)00179-5. 
15. Kettimuthu KP, Kini A, Manickam AS, Lourthuraj AA, Venkatraman A, Subramani $S$, et al. Cleistanthus collinus poisoning affects mitochondrial respiration and induces oxidative stress in the rat kidney. Toxicol Mech Methods 2019;29:561-568. DOI: 10.1080/15376516.2019.1624905.

16. Kumar M, Ramaswamy S, Jayanthi M, Raveendran R. Alphaadrenergic receptor blocking effect of Cleistanthus collinus (Roxb.) Benth. and Hook F. Leaf extract on guinea pig isolated smooth muscle preparations. Indian J Exp Biol 2011;49:339-342.

17. Parasuraman $S$, Raveendran R. The effects of aqueous extract of Cleistanthus collinus (Roxb.) (Euphorbiaceae) leaves on rat blood pressure. Pharmacognosy Res 2012;4(3):178-180. DOI: 10.4103/0974-8490. 99086.

18. Jose VM, Anand KN, Jeyaseelan L, Ernest K, Kuruvilla A. Effect of potassium channel modulators on toxicity of Cleistanthus collinus. Indian J Exp Biol 2004;42(1):81-85.

19. Nandakumar NV, Vijayalakshmi KM. Experimental myasthenic crisis like neuromuscular impairement with Cleistanthus collinus leaf extract administration in rat. Physiother Res 1996;10:121-126.

20. Damodaram P, Manohar IC, Kumar DP, Mohan A, Vengamma B, Rao $\mathrm{MH}$. Myasthenic crisis-like syndrome due to Cleistanthus collinus poisoning. Indian J Med Sci 2008;62(2):62-64. DOI: 10.4103/00195359.39368.
21. Mohan A, Naik GS, Harikrishna J, Kumar DP, Rao MH, Sarma K, et al. Cleistanthus collinus poisoning: experience at a medical intensive care unit in a tertiary care hospital in south India. Indian J Med Res 2016;143:793-797. DOI: 10.4103/0971-5916.192068.

22. Subrahmanyam DK, Mooney T, Raveendran R, Zachariah B. A clinical and laboratory profile of Cleistanthus collinus poisoning. J Assoc Physicians India 2003;51:1052-1054.

23. Devaprabhu S, Manikumar S, David SS. Toxico-epidemiology and prognostic profile of patients with Cleistanthus collinus poisoning. Indian J Trauma Anaesth Crit Care 2007;8:642-646.

24. Bammigatti C, Surynarayana BS, Harichandra Kumar KT, Ganesh Kumar S. Pattern and outcome of Cleistanthus collinus (Oduvanthalai) poisoning in a tertiary care teaching hospital in South India. J Forensic Leg Med 2013;20:959-961. DOI: 10.1016/j.jfIm. 2013.08.011.

25. Benson BE, Hoppu K, Troutman WG, Bedry R, Erdman A, Höjer J, et al. American Academy of Clinical Toxicology; European Association of Poisons Centres and Clinical Toxicologists. Position paper update: gastric lavage for gastrointestinal decontamination. Clin Toxicol 2013;51:140-146. DOI: 10.3109/15563650.2013.770154.

26. Raja G, Kumaran SS, Chandrasekaran VP. Outcome of Cleistanthus collinus poisoning with and without charcoal. Acad Emerg Med 2007;14(5):e111. DOI: 10.1197/j.aem.2007.02.010. 